\title{
Embedded librarianship: questions and answers from librarians in the trenches
}

Author(s):

Cassandra Kvenild ((ckvenild@uwyo.edu) is Associate Librarian at the University of Wyoming, Laramie, Wyoming, USA.)

Beth E. Tumbleson (Miami University, Middletown, Ohio, USA.)

John J. Burke (Miami University, Middletown, Ohio, USA.)

Kaijsa Calkins (University of Wyoming, Laramie, Wyoming, USA.)

Citation:

Cassandra Kvenild, Beth E. Tumbleson, John J. Burke, Kaijsa Calkins, (2016) "Embedded librarianship: questions and answers from librarians in the trenches", Library Hi Tech News, Vol. 33 Iss: 2, pp.8 - 11

DOI

http://dx.doi.org/10.1108/LHTN-11-2015-0078

\section{Purpose}

This paper aims to share the current state of embedded librarianship in learning management systems as reported by academic librarians. The paper highlights the best practices, as well as continuing questions, in the field of embedded librarianship.

\section{Design/methodology/approach}

The authors collected participant feedback in two active, participatory panel discussions at national conferences. The open forums were centered on three guiding themes of embedded librarianship: building connections with faculty and students; utilizing technology tools; and providing information literacy and assessment. Participants answered directed questions, and their responses were recorded and analyzed for this paper.

\section{Findings}

Librarians report an increasing demand for library services in learning management systems. Collaboration and partnerships across campus are required for successful embedded librarian projects. Technology tools continue to evolve and change, and most librarians can anticipate using multiple learning management systems over time. There is an ongoing need for professional development in online library instruction and assessment.

\section{Originality/value}

This paper provides a snapshot of the current state of embedded librarianship in learning management systems. It offers insights about what academic librarians value, what they have learned and what concerns they still have about library instruction in online environments.

Keywords:

Library services, Library instruction, Information literacy, Learning management systems, Distance learning, Embedded librarianship

Type: 
Research Paper

Publisher:

Emerald Group Publishing Limited

\section{Article}

\section{Introduction}

As learning management systems (LMSs) have become widely adopted in higher education, both for delivery of distance learning courses and for hybrid instruction on campus, librarians increasingly utilize the LMS to teach and interact with students. This model of embedded librarianship in the LMS continues to evolve, and the authors wanted to engage practitioners in a guided conversation about how librarians utilize the LMS to embed themselves in courses. At the most recent meetings of the Association of College and Research Libraries (March 2015) and of the Distance Libraries Conference (April 2014), the authors posed several discussion questions about embedded librarianship within learning management systems to large audiences of librarians. These open forums were an opportunity to learn from librarians, whether experienced or new to embedded librarianship.

The authors served as panelists and provided structure, background and a set of predetermined questions. The discussion was structured around a few guiding themes, including building connections with faculty, utilizing technology tools, providing information literacy instruction and assessing outcomes. The audience provided insight, answers and still more questions about embedded librarianship. Their responses were captured live with the hope that they could be shared more broadly. This article will provide a glimpse of the authors' perspectives on embedded librarianship in LMSs, and it will also outline what we learned from librarians about embedded librarianship in the current instructional climate.

\section{Connections and expectations}

LMS-embedded librarians are effective only when they connect with students in the LMS, despite their extensive training and experience in information literacy. Understanding that students do not think and act like scholars in research goes a long way in shaping outreach efforts in the LMS. Knowing that students are likely searching Google and Wikipedia first goes with the job. Embedded librarians can anticipate the usual array of information barriers and issues students will encounter, based on their work with students in face-to-face one shots and previous sections of online classes. Yes, students appreciate the convenience of links to library databases and finding tools, as well as embedded video tutorials next to their LMS research assignments. Some may wonder what research advantage there is in looking at the posted offerings. Students may value personal research guidance, but they may not be receptive until they know something about you. They wonder who this stranger may be, and how trustworthy this person is. One does not bare one's research missteps until there is some level of confidence or desperation.

How do you forge meaningful faculty - student - librarian interactions in the LMS?

LMS-embedded librarians report success when they are proactive in making connections with faculty and students. They recommend inviting teaching faculty to collaborate in their LMS courses through a range of marketing efforts each semester, both in-person and electronically, both individually and to groups. Those who partner with LMS-embedded librarians often extend the program by word-of-mouth marketing with colleagues. Once LMS-embedded librarians address instructors' information literacy priorities and highlight the relevant databases and digital collections, available library services and technology equipment and offer research strategies, consultations and digital assets, teaching faculty may be won over and become allies. Participants suggested showing 
academic faculty a variety of digital learning objects that could be used in their course: video tutorials, LibGuides, academic integrity interactive games and citation managers for instance. This approach allows professors to select the information literacy learning outcomes and support them. Librarians can also offer to review a professor's research assignments and suggest redesign ideas that incorporate the latest research tools and collections.

What does effective learning management system communication with students look like?

Students may have had limited exposure to librarians, as school districts continue to eliminate these positions. Once again, it is imperative that LMS-embedded librarians be proactive, approachable, knowledgeable and become trusted research companions. By posting a picture, providing contact information, embedding a chat widget, creating an "Ask the Librarian" discussion or embedding a personal introductory video, it becomes easier for students to share their research issues.

The embedded librarian might post an announcement that is emailed to the entire class roster with research tips specific to the upcoming course assignment. The librarian can also send additional emails with timely research techniques that are easy to scan, with linked resources and tutorials that anticipate typical research dilemmas. This alleviates the need for students to ask, preserving dignity, yet they benefit from learning about unfamiliar approaches to research.

What do students expect of an embedded librarian?

The embedded librarian's aim is to explain, in plain language, the complexities of the academic library system. This can be accomplished in part by creating video tutorials that clarify the research process and demonstrate efficient online searching using the discovery service, subject databases and portals. It may mean building course and subject LibGuides to lead student researchers towards relevant databases, digital collections, authoritative Web sites and time-saving tools for finding and citing sources. In these ways, the embedded librarian empowers the students.

When the embedded librarian answers students' questions and assists in solving their research problems, such as getting a full-text article, explaining how to gain remote access or describing how to cite an email, students are appreciative. The librarian becomes a member of each students' personalized learning team. In a digital world, librarians have observed that people still value personal relationships and guidance at critical stages of research. Showing up in students' LMS courses as embedded librarians extends the reach of librarians, who might otherwise remain strangers, seemingly outside the teaching, learning and research mission of the university.

\section{Technology tools}

Embedded librarianship in the LMS provides many opportunities for librarians to put technology to work in sharing resources with students and communicating with them. The universe of technology tools that librarians may draw upon for these purposes includes features within the LMS, library databases and other informational resources, instructional content created by librarians and other third-party Web applications. During our panel discussions, we shared some approaches for designing the placement of embedded librarian resources within the course and some considerations on locating and choosing tools to implement. We then asked participants to respond to three questions about their technology use. We were curious to learn how librarians were utilizing the LMS and other tools and to have them help us identify issues they faced in using technology.

The initial presentation of technology issues and decision points for embedded librarians included the following observations:

Design: Librarians can imagine their embedded librarian presence as a course within a course and should design their embedded resources, technologies and services with that approach in mind. 
Communication and sharing content: These are the two main purposes for embedded librarians to use technology. While the use of communication tools will start anew with each new course, other content added to the course (such as database links, LibGuides and tutorials) may be built fresh, reused from previous semesters or borrowed from other librarians.

LMS tools and Web apps: Embedded librarians not only may use communication options and content-sharing technologies from within the LMS but also can choose other applications and software they find on the Web to interact with students and provide guidance on finding information for course assignments.

Finding alternatives: In keeping with the issue above, this question brought focus on finding other options for LMS-provided technologies (e.g. better threaded discussion options, wikis or Web conferencing options).

Copyright concerns: While most items that embedded librarians might add to courses are links to licensed content or original content they create, there may be needs to link streaming media or other content that would require copyright permission or consideration of Fair Use principles.

E-learning support: Librarians were asked to consider whether their e-learning unit is helpful to work with and whether or not they provide direct support to librarians working in embedded courses.

LMS migrations: Many colleges and universities have changed LMS providers, and for some, it is a recurring phenomenon. Librarians have to be prepared to move content from one LMS to another and to learn new tools for doing their work in the adopted LMS.

Immediate needs and longer-term skills: The focus here is on the initial training and larger professional development investments that librarians may wish to make as they build embedded librarian programs. We were curious to know how librarians were approaching training: do they use professional development mainly as a short-term effort to meet immediate needs or with longer-term attention to instructional design skills and advanced LMS knowledge.

Following the presentation, we asked the participants the following three questions. Their responses are summarized below each one.

What technology tools are you using in your embedded courses?

The librarians responded with a list of items they include in their embedded courses. They mentioned using instant messaging, chat and discussion board tools that are part of the LMS. They also cited the ability to create modules in the course that they could dedicate to library resources. Web applications beyond the LMS included LibGuides (to create research guides), Prezi (for interactive presentations), Screencast-O-Matic and Jing (for screencast videos), WebEx (for Web conferencing) and search widgets for the library's discovery layer. One other item mentioned was including open educational resources as alternatives to textbooks.

What does the LMS add to your embedded librarian experience?

Librarians found that the asynchronous nature of the LMS made it possible to check and respond to student discussion board posts, even with many class sections to cover. They also noted how easy it is for students to find databases that they recommend. While some librarians only have embedded librarians in online courses, those who work with both online and face-to-face courses shared that online students interacted with librarians more often. A final positive reason for using the LMS was the ability for students to make online appointments with librarians.

What technology challenges are you facing as an embedded librarian?

The challenges shared in the sessions included some specific LMS issues, such as embedding a LibGuide in Canvas. More general LMS questions involved the role assigned to librarians in the 
LMS: some librarians are given the same level of access as course instructors, while others are in more limited "teaching assistant" role that limits their abilities to post content. A strong recommendation was made for institutions to create specific "librarian" roles in their LMS that would maximize possibilities for creating course content and participating in class discussions while perhaps removing access to the grade book. Beyond the LMS, librarians wondered about whether to have students use cloud-based apps for storage or other creative purposes, with special emphasis on security concerns.

Technology will continue to be a constant in embedded librarianship, both expanding librarians' and students' choices for information resources and requiring continual professional development and re-imagination of the embedded presence. As LMS continues to evolve, librarians may see more of their needs met entirely within the learning system and lessen the need for some third-party applications. On the other hand, new methods for bringing library resources into the course will continue to require troubleshooting and an enhanced understanding of LMS capabilities. The success of librarians' outreach to students depends on librarians making the best choices from the technology available.

\section{Information literacy}

While embedded librarians have a lot of technological tools at their disposal to facilitate their work with students, it takes thoughtful planning to provide excellent instruction and research support.

The presentations provided less background on information literacy than other topics because the audience of academic librarians was very familiar with instruction and related concepts like mapping learning objectives to standards and assessing services and student learning.

We asked participants four questions about information literacy, instruction and assessment.

How are you incorporating standards in your embedded teaching?

Librarians reported that they almost always use existing institutional learning objectives and core competencies and map them to library instruction. Librarians have successfully incorporated the ACRL Standards for Information Literacy in Higher Education but are grappling with the new ACRL Framework for Information Literacy. Some say their current institutional instruction and assessment plans are not flexible enough to include the framework, and some are only using it to start useful conversations with faculty. Others are using the framework to revisit the library mission, set up policies and procedures, map to disciplinary or professional standards and connect to accreditation. Embedded librarians are also using rubrics in Canvas or other LMSs.

How do you measure the impact of an embedded librarian on student learning?

Participants shared that they are changing the way they view embedded work at their institutions from being an extension of reference to being an instruction activity. Librarians are using a wide variety of methods for assessing student learning and librarian impact on student success. Direct assessments range from the simple, such as pre- and post-tests and quizzes following instruction or tours to more labor-intensive activities such as citation analysis projects. Indirect methods include collecting academic faculty perceptions and student feedback. Participants have goals for future assessment, too. Some librarians are planning longitudinal tracking of the impact of library instruction on students.

What in-roads have you made in connecting your embedded instruction to larger curriculum goals?

Librarians find it hard to balance instruction for general education courses with the work they do with programs and majors. Some are embedding in all courses by creating content and partnering with instructional designers to connect instructional materials with course management sites. 
Others report that they are keeping statistics on emails and other contacts from students and track time spent embedding to demonstrate how embedded work connects to larger instruction goals. Librarians note that it is challenging to directly compare different types of embedded work.

What is your long-range plan for embedded instruction?

Participants report a wide range of goals for their embedded work. Some are working toward moving more library instruction completely online to lighten the face-to-face instruction load. Some would like to adopt a strategy similar to tiered reference, moving the lower-level instruction online by using tutorials and other learning objects, so that they can prioritize on more challenging research courses for face-to-face instruction. Others want to integrate information literacy instruction into the curriculum and are working toward becoming a part of campus or program curriculum efforts.

\section{Conclusions and ongoing questions}

The practice of embedded librarianship in LMSs continues to grow and evolve rapidly. Once the niche of distance librarians serving online-only students, library instruction in a LMS is now commonplace across campuses and disciplines. Librarians report that demand and expectations for a library presence in the LMS are widespread. Indeed, many librarians worry that the demand for instruction online exceeds their ability to provide it. There is a continued need to answer the questions of how to scale LMS library instruction and how to be embedded with a low ratio of librarians to students.

Librarians looking to enhance their presence in the LMS must be politically savvy. Successful embedded librarians emphasize the importance of building partnerships and gaining the trust of teaching faculty, along with the information technology and e-learning units. On some campuses, access to the LMS is closely guarded, whereas other schools hold out hope for a librarian embedded in every course. Careful attention to the local climate is advised.

Librarians indicate an ongoing need for professional development to support online library instruction. Librarians want continued training in instructional design for LMS environments, in the best uses of technology in the LMS and in assessing student learning and demonstrating the value of librarians in online learning. While participants expressed confidence in tailoring their instruction to meet local priorities and ACRL standards, detailed questions about the LMS and online instruction persist: How secure is cloud storage? What is the best way to encourage and manage discussion boards? How can librarians leverage data automatically collected by the LMS to assess their impact? Some of these questions can be addressed by training; others call for the development of nurturing communities of LMS librarians. One specific suggestion we heard was to hold LMS discussion groups for librarians at conferences to share tips and questions about particular vendors and LMS environments. Another librarian suggested that LMS-embedded librarians explore creating common assessments for information literacy. It is critical that the community of librarians working within LMSs continue to share their experiences and expertise and develop ongoing research about their work.

\section{About the author(s)}

Cassandra Kvenild is an Interim Associate Dean and the Head of the Learning Resource Center at the University of Wyoming Libraries. She is the co-author (with Melissa Bowles-Terry) of Classroom Assessment Techniques for Librarians (ACRL 2015) and the co-editor (with Kaijsa Calkins) of The Embedded Librarian's Cookbook (ACRL 2014) and Embedded Librarians: Moving Beyond One-Shot Instruction (ACRL 2011). She was awarded ACRL's Routledge Distance Learning Librarianship Award in 2011. She is a graduate of the University of Washington iSchool. 
Beth E. Tumbleson is an Assistant Director of the Gardner-Harvey Library, Miami University Middletown and holds the rank of an Associate Librarian. She co-authored Embedding

Librarianship in Learning Management Systems (ALA Neal-Schuman, 2013) with John Burke and has published books chapters and journal articles on LMS-embedded librarianship. She is a graduate of Simmons School of Library Science, Boston.

John J. Burke is the Director of the Gardner-Harvey Library at Miami University Middletown and holds the rank of the Principal Librarian. He is the co-author (with Beth Tumbleson) of Embedding Librarianship in Learning Management Systems (ALA Neal-Schuman, 2013) and the author of books on library technology and makerspaces. He earned his MSLS at the University of Tennessee.

Kaijsa Calkins is an Associate Librarian in the Research \& Instruction Department at the University of Wyoming Libraries. She is subject liaison to humanities and cultural studies departments and teaches courses on library research and for the University Honors Program. Her publications include several works on embedded librarianship, including two books co-edited with Cassandra Kvenild. She earned her MLIS at the University of Washington iSchool. 